\title{
The efficacy of Stereotactic body radiation therapy and the impact of systemic treatments in oligometastatic patients from prostate cancer
}

\author{
Ciro Franzese $^{1}$ (D) | Paolo Andrea Zucali ${ }^{2}$ (D) | Lucia Di Brina ${ }^{1}$ | \\ Giuseppe D’Agostino $^{1}$ | Pierina Navarria ${ }^{1}$ | Davide Franceschini ${ }^{1}$ \\ Armando Santoro $^{2,3}$ | Marta Scorsetti ${ }^{1,3}$
}

${ }^{1}$ Radiotherapy and Radiosurgery

Department, Humanitas Clinical and

Research Hospital, Milan-Rozzano, Italy

${ }^{2}$ Medical Oncology and Hematology

Department, Humanitas Clinical and

Research Hospital, Milan-Rozzano, Italy

${ }^{3}$ Department of Biomedical Sciences,

Humanitas University, Milan-Rozzano, Italy

Correspondence: Ciro Franzese,

Radiotherapy and Radiosurgery

Department, Humanitas Clinical and

Research Hospital, Via Manzoni 56,

Rozzano, MI, Italy

(ciro.franzese@humanitas.it).

\begin{abstract}
Background: Diagnoses of oligometastatic prostate cancer (PC) increased in the recent years thanks to the advancement in imaging and more effective systemic therapies. Here we evaluate the efficacy of Stereotactic Body Radiation Therapy (SBRT) in oligorecurrent and oligoprogressive PC.

Methods: We included patients with a maximum of five metastases diagnosed in a maximum of two target organs. Concomitant treatment with hormonal therapies or chemotherapies was allowed. End points of the present study were the outcome in terms of Local control of treated metastases (LC), out-field progression free survival, overall progression free survival (PFS), and overall survival.

Results: We included in the analysis 64 patients treated on 90 metastases. Fifty (78.1\%) patients were treated on lymph nodes, $2(3.1 \%)$ patients simultaneously on lymph node and bone while $10(15.7 \%)$ patients on bone only. Lung metastases were treated in 2 (3.1\%) patients. Thirty-seven $(57.81 \%)$ were without androgen deprivation therapy when treated with SBRT. Median follow-up was 15.2 months. Rates of LC at 6-, 12-, and 18- months were $94 \%, 88 \%$, and $84 \%$, respectively. Oligoprogressive patients compared to oligorecurrent (HR 9.10, $P=0.049$ ) and prolongation of time from diagnosis of metastases to SBRT (HR 1.03, $P=0.047$ ) were associated with worse LC. Median PFS was 6.6 months (range 1.1-42.4). Castration resistant patients experienced worse PFS compared to castration sensitive group (HR 2.12, $P=0.021)$.
\end{abstract}

Conclusions: Stereotactic body radiation therapy seems to be an effective treatment for metastases from PC. Prospective trials are necessary to better define selection of patients and to evaluate combination of SBRT and new systemic drugs in castration resistant patients.

\section{KE Y W O R D S}

hormonal therapy, oligometastases, prostate cancer, stereotactic body radiation therapy, systemic treatment

This is an open access article under the terms of the Creative Commons Attribution License, which permits use, distribution and reproduction in any medium, provided the original work is properly cited. 


\section{INTRODUCTION}

In 1995, Hellman and Weichselbaum coined the term "oligometastasis" as an intermediate state between localized tumor and widespread diffuse disease. ${ }^{1}$ Since that year several studies focused on the attempt to understand the benefit from local therapies on isolated metastases, with the conviction that oligometastatic patients are affected by a disease with a biology different from the classic concept of metastasis. ${ }^{2}$

Prostate cancer (PC) can metastasize to different sites. According to Harada et $\mathrm{al}^{3}$, in an autoptic series on 136 patients, $36 \%$ and $32 \%$ were identified with one and two bone lesions, respectively. The number of metastases that defines the oligometastatic state in PC is still unclear. A wide variability exists in the recent literature. Some studies limited the number of metastases to five $e^{4}$ and the majority of published trials included a maximum of three lesions. ${ }^{5,6}$ Singh et al $^{7}$ reported that a number of metastases limited to five lesions, developed during follow-up after curative treatment of primary tumor, was significantly associated to better 5 -year survival $(73 \%$ vs $43 \%$ of patients with more than five metastases). Diagnoses of oligometastatic PC increased in the recent years; possible causes of this increase include the advancement in imaging with new PET tracers, and the longer survival improved by more effective systemic therapies. ${ }^{8-10}$

According to the study of Sobol et al, ${ }^{11}$ among 2466 men underwent choline-PET for suspected relapse, 134 $(67 \%)$ were diagnosed with metastatic disease, $(25 \%$ with axial or appendicular bone, and $75 \%$ with recurrences in the soft tissue]. De Bruycker et al analyzed prospectively 208 patients candidate to PET scan and showed that 153 patients $(74 \%)$ had low-volume recurrence, defined as isolated local recurrence or with $\leq 3$ metastases (with or without local recurrence). Among 153, 119 had only metastatic recurrence. ${ }^{12}$ Historically, PC with any number of metastases was treated with systemic therapy, more commonly androgen deprivation therapy (ADT). Optimal management of oligometastatic patients is still to be defined. No real advantage from systemic treatments has been demonstrated in early recurrent PC. According to Duchesne et al, ${ }^{13}$ in the TOAD trial there was no improvement of survival from immediate ADT in PSA-recurrent patients $(P=0.10)$. Gravis et al analyzed patient subgroups from the CHAARTED and GETUG-AFU15 according to metastatic burden. While the analysis showed survival benefit from adding immediate docetaxel to ADT in high volume patients, no benefit was observed for low volume disease with HR of 1.03 (95\% CI: $0.77 ; 1.38)$. The role of local approaches in oligometastatic PC patients has been investigated recently in few reports. ${ }^{14-16}$ Decaestaker et $\mathrm{al}^{17}$ treated 50 patients with 70 metastatic lesions from PC; the authors included hormone sensitive patients with up to three synchronous metastases in bones or lymph nodes. Local control was reached in $100 \%$ of sample and median PFS was 19 months with $3 / 4$ of patients recurring with a maximum of three metastases. Here we evaluate the efficacy of Stereotactic Body Radiation Therapy (SBRT) in oligorecurrent and oligoprogressive PC and the impact of systemic therapies on the behavior of disease.

\section{2 | MATERIALS AND METHODS}

\section{1 | Study population}

We included in this single institution analysis patients with histologically confirmed diagnosis of prostate adenocarcinoma, treated with surgery +- adjuvant/salvage radiotherapy (RT) or radical $\mathrm{RT}$, which developed metachronous metastases during follow-up from 2009 to 2016. All cases were presented to and approved by the multidisciplinary uro-oncology team. The local ethics committee approved the analysis. Patients were candidate to SBRT if a maximum of three metastases with a maximum diameter of $5 \mathrm{~cm}$ were diagnosed in 1-2 organs (eg bone and lymph node). Concomitant treatment with hormonal therapies or chemotherapies was allowed. All patients were staged with $11 \mathrm{c}$-choline PET or CT scan together with $99 \mathrm{mT}$ c-bone scan. The study was conducted in accordance with Good Clinical Practice guidelines, the ethical principles of the Declaration of Helsinki and local regulations. Exclusion criteria were patients with diagnosis of synchronous metastases.

\section{2 | Techniques of radiotherapy}

The clinical target volume (CTV) was equal to gross tumor volume (GTV) and was delineated on simulation CT imaging, coregistered with MRI scan or PET scan when available. In-vein contrast for $\mathrm{CT}$ was used in case of treatment of lymph node metastases. In case of disease located into organ subject to internal movement (such as lung), patients were simulated with 4D-CT scan. All patients were positioned supine, with a thermoplastic mask, both for abdomen and pelvis. An isotropic margin of 5-10 mm, depending on disease site and dimensions, was added to CTV to obtain the planning target volume (PTV). In case dose constraints for organs at risk were not met, dose to PTV was deescalated. All patients were treated with Volumetric Modulated Arc Therapy technique. The patient's position was evaluated daily with Cone-beam CT imaging before each treatment session. Patients treated with systemic therapy were submitted to SBRT for comparison on new isolated sites of disease (Oligorecurrence) or for progression of few sites while the remaining were controlled by systemic therapy (Oligoprogression). 


\section{3 | Response assessement}

First evaluation was planned 3 months after the end of the SBRT and then every 3 months for the first year and every 6 months from the second to the fifth year. Clinical evaluation and PSA values were obtained for every follow-up visit. Diagnostic imaging (CT, Choline-PET or MRI scan) was planned at physician choice. In general reassessments with imaging were planned in case of three rising PSA values after response or in case of PSA rise above the pre-SBRT value or in case of new potentially disease related symptoms. Tumor response was classified according to European Organization for Research and Treatment of Cancer Response Evaluation Criteria In Solid Tumors (EORTC-RECIST) criteria version 1.16. PET Response Criteria in Solid Tumors (PERCIST) ${ }^{18}$ were used to evaluate metabolic response in patients who underwent PET scan for restaging. Globally castration resistant patients' were evaluated after treatment according to Prostate Cancer Clinical Trials Working Group 3 (PCWG3). ${ }^{19}$

\section{4 $\quad$ Statistical analysis}

Data were collected and analyzed retrospectively. End points of the present study included the outcome in terms of local control of treated metastases (LC), out-field progression free survival (OF-PFS), progression free survival (PFS), and overall survival (OS). Local control was analyzed at patient's level and defined as the time from the beginning of SBRT to the infield progression of treated metastases or last follow-up. Outfield progression free survival was defined as the time from the SBRT to the onset of new metastases. Additionally PFS was defined as the time from SBRT to the evidence of in-field or out-field progression or increase of PSA. Overall survival was calculated from the SBRT to either death or last followup. Univariate analysis was performed with the log-rank test, and Cox proportional hazards regression was used to estimate hazard ratios (HR). Multivariable Cox regression analysis was performed to evaluate the association between clinical factors and survival, with a significance level of $P<0.05$. Statistical calculations were performed using STATA, version 14 (StataCorp 2015, College station, Texas: StataCorp LP.).

\section{3 | RESULTS}

A total of 64 PC patients with 90 metastases were treated with SBRT. Patients' characteristics are summarized in Table 1. Median age was 71.8 years (range 51.3-82.9) and median PSA at first diagnosis (iPSA) was $9.95 \mathrm{ng} / \mathrm{mL}$ (range 3.7-146). Forty-eight (75\%) patients were treated on primary tumor with radical surgery while $5(7.81 \%)$ patients underwent radical RT. The remaining patients underwent ADT (7.81\%) or high intensity focused ultrasound $(9.38 \%)$ as first treatment. Among
TAB LE 1 Patient's characteristics

\begin{tabular}{|c|c|}
\hline & $\mathbf{N}(\%)$ \\
\hline Age median (range) & $71.8(52.9-82.9)$ \\
\hline$\leq 65$ & $9(14 \%)$ \\
\hline$>65$ & $55(86 \%)$ \\
\hline \multicolumn{2}{|l|}{ PS } \\
\hline 0 & $39(60.9 \%)$ \\
\hline 1 & $19(29.7 \%)$ \\
\hline 2 & $6(9.4 \%)$ \\
\hline \multicolumn{2}{|l|}{ Gleason score } \\
\hline$\leq 8$ & $47(73.4 \%)$ \\
\hline$>8$ & $17(26.6 \%)$ \\
\hline PSA at diagnosis, median ng/mL (range) & $9.95(3.7-46)$ \\
\hline \multicolumn{2}{|l|}{ NCCN Risk group } \\
\hline Low risk & $2(3.1 \%)$ \\
\hline Intermediate risk & $35(54.7 \%)$ \\
\hline High risk & $27(42.2 \%)$ \\
\hline \multicolumn{2}{|l|}{ Initial treatment } \\
\hline Surgery & $13(20.3 \%)$ \\
\hline Surgery + Radiotherapy & $35(54.7 \%)$ \\
\hline HIFU & $6(9.4 \%)$ \\
\hline ADT & $5(7.8 \%)$ \\
\hline Radiotherapy & $5(7.8 \%)$ \\
\hline $\begin{array}{l}\text { Time to biochemical relapse, median months } \\
\text { (range) }\end{array}$ & $32.8(0-169.6)$ \\
\hline Time to metastases, median months (range) & $34.8(0-194)$ \\
\hline \multicolumn{2}{|l|}{ Number of treated metastases } \\
\hline 1 & $41(64 \%)$ \\
\hline 2 & $20(31.2 \%)$ \\
\hline 3 & $3(4.7 \%)$ \\
\hline \multicolumn{2}{|l|}{ Site of metastases } \\
\hline Lymph node & $52(81.2 \%)$ \\
\hline Bone & $10(15.6 \%)$ \\
\hline Lung & $2(3.1 \%)$ \\
\hline \multicolumn{2}{|l|}{ American joint committee on cancer TNM staging } \\
\hline N1 & $35(54.7 \%)$ \\
\hline M1a & $15(23.4 \%)$ \\
\hline M1b & $12(18.7 \%)$ \\
\hline M1c & $2(3.1 \%)$ \\
\hline \multicolumn{2}{|l|}{ Oligorecurrence vs oligoprogressive disease } \\
\hline Oligorecurrence & $62(96.9 \%)$ \\
\hline Oligoprogression & $2(3.1 \%)$ \\
\hline
\end{tabular}

patients treated with surgery, 35 patients (54.6\%) had adjuvant or salvage RT. At first biochemical relapse median PSA was $1.3 \mathrm{ng} / \mathrm{mL}$ (range 0.03-146) and median time from diagnosis primary tumor to detection of metastases was 34.8 months (range 0-194.3). Median time from detection of metastases to 
SBRT was 1.85 months (range 0.23-58.5). Median PSA before SBRT was $2.16 \mathrm{ng} / \mathrm{mL}$ (range 0.03-28.62). The majority of patient performed PET before the RT treatment while only two patients had CT scan for diagnosis of metastatic disease. Patients were more commonly treated on abdominal or pelvic lymph nodes only (50 patients, $78.1 \%$ ). Two (3.1\%) patients were treated simultaneously on lymph node and bone metastases while $10(15.7 \%)$ patients on bone metastases only. Lung metastases were treated in $2(3.1 \%)$ patients. According to American Joint Committee on Cancer (AJCC) TNM Staging System For Prostate Cancer (8th ed., 2017), patients were classified as $\mathrm{N} 1(35 ; 54.7 \%)$ if only regional lymph node were involved, M1a $(15 ; 23.4 \%)$ if nonregional lymph nodes metastases were detected, M1b $(12 ; 18.7 \%)$ if treated for bone metastases. Visceral metastases were classified as M1c (2; $3.1 \%$ ). Globally $45.3 \%$ (29) patients were classified as M1. Forty-one $(64.1 \%)$ patients were treated with SBRT on one single metastasis while $20(31.2 \%)$ and $3(4.7 \%)$ patients on two and three metastases, respectively. Only two patients had other sites of disease not treated with SBRT but controlled by systemic therapy.

Radiotherapy was delivered with a median dose of 42 Gy (range 18-60) in 2-8 fractions. Median dose per fraction was 7.5 Gy (range 5-12). Thirty-seven (57.81\%) were without ADT when treated with SBRT. Twenty-seven patients were treated with ADT when submitted to radiation. Nineteen (29.7\%) patients were classified as castration-resistant when treated with SBRT on metastases. Treatment's characteristics are summarized in Table 2.

Median follow-up time was 15.2 months (range 3-101.4). Best radiologic response after SBRT was classified as complete response in $41(64.1 \%)$ patients, partial response in 10 (15.6\%) patients, and stable disease in $2(3.1 \%)$ patients. Eight patients didn't performed radiological examination for evaluation of response and were evaluated only with PSA value. Overall median value of nadir PSA (nPSA) reached after SBRT was $1.64 \mathrm{ng} / \mathrm{mL}$ (range 0-45.05). Median nPSA in patients without progression after RT was $0.39 \mathrm{ng} / \mathrm{mL}$ (range 0.01-5.8). Biochemical response was observed in 25 patients.

Local control of treated metastases at 6-, 12-, and 18months was $94 \%$ (95\% CI: 0.56-0.80), $88 \%$ (95\% CI: $0.25-$ 0.51 ), and $84 \%$ (95\% CI: 0.13-0.38), respectively. Median time to in-field progression was 14.1 months (range 2.5-101.4). Figure 1 illustrates LC Kaplan-Meier analysis. At univariate analysis oligoprogressive patients compared to oligorecurrent (HR 9.10, 95\% CI: 1.00-82.32, $P=0.049$ ) and prolongation of time (per unit of month) from the diagnosis of metastases to SBRT (HR 1.03, 95\% CI: $1.00-1.07, P=0.047$ ) were associated with a worse in-field control. At multivariable analysis none of the analyzed factors was statistically significant even if borderline, as summarized in Table 3 .

Thirty-eight (59.3\%) patients were diagnosed with outfield distant metastases with a median time of 8.1 months
TA B LE 2 Treatments' characteristics

\begin{tabular}{|c|c|}
\hline & $\mathbf{N}(\%)$ \\
\hline \multicolumn{2}{|l|}{ Systemic therapy during RT } \\
\hline No & $37(57.8 \%)$ \\
\hline Yes & $27(42.2 \%)$ \\
\hline \multicolumn{2}{|l|}{ Previous ADT } \\
\hline No & $16(25 \%)$ \\
\hline Yes & $48(75 \%)$ \\
\hline \multicolumn{2}{|l|}{ Previous chemotherapy } \\
\hline No & $51(79.7 \%)$ \\
\hline Yes & $13(20.3 \%)$ \\
\hline \multicolumn{2}{|l|}{ Lines of systemic therapies } \\
\hline 0 & $15(23.4 \%)$ \\
\hline 1 & $25(39 \%)$ \\
\hline 2 & $12(18.7 \%)$ \\
\hline 3 & $12(18.7 \%)$ \\
\hline \multicolumn{2}{|l|}{ Castration sensitive vs resistant disease } \\
\hline Sensitive & $45(70.3 \%)$ \\
\hline Resistant & $19(29.7 \%)$ \\
\hline $\begin{array}{l}\text { Time from M+ to SBRT, median months } \\
\text { (range) }\end{array}$ & $1.8(0.2-58.5)$ \\
\hline PSA before SBRT, median ng/mL (range) & $2.16(0.03-28.62)$ \\
\hline SBRT total dose, median Gy (range) & $42(18-60)$ \\
\hline 5 Gy x 5 & 2 \\
\hline 5 Gy x 6 & 3 \\
\hline 6 Gy x 5 & 9 \\
\hline 6 Gy x 6 & 7 \\
\hline 7.5 Gy x 6 & 15 \\
\hline 8 Gy x 4 & 1 \\
\hline 9 Gy x 2 & 1 \\
\hline 10 Gy x 4 & 6 \\
\hline 10.5 Gy x 4 & 5 \\
\hline 12 Gy x 4 & 15 \\
\hline BED3, median Gy (range) & $157(66.6-240)$ \\
\hline$\leq 100$ & $15(23.4 \%)$ \\
\hline$>100$ & $49(76.6 \%)$ \\
\hline
\end{tabular}

(range 1.6-46.4). In particular, out-filed progression was observed in 25 castration sensitive patients and 13 castration resistant patients. Rates OF-PFS were 78\% (95\% CI: 65\%$86 \%$ ), $52 \%$ (95\% CI: $38 \%-65 \%$ ), and $37 \%$ (95\% CI: $23 \%-$ $51 \%$ ) at 6-, 12-, and 18- months, respectively.

Globally 44 (68.7\%) patients had in-field or out-field progression of disease after SBRT with a median PFS of 6.6 months (range 1.1-42.4). Rates of PFS at 6-, 12-, and 18- months were $70 \%$ (95\% CI: $56 \%-80 \%$ ), $38 \%$ (95\% CI: $25 \%-51 \%$ ), and $25 \%$ (95\% CI: $13 \%-38 \%$ ) as in Figure 2. Analysis of correlation between risk factors and PFS is summarized in Table 4. Castration resistant patients 


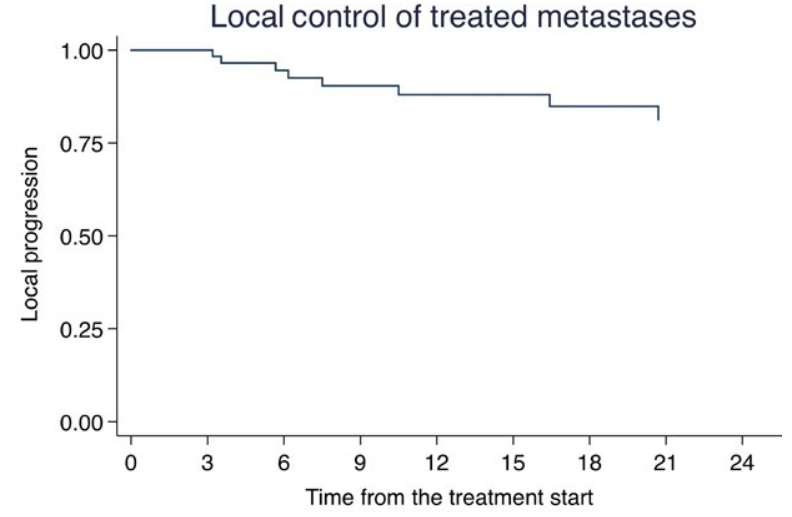

Number at risk $\begin{array}{lllll}62 & 47 & 35 & 26 & 23\end{array}$

F I G URE 1 Kaplan-Meier of Local control of treated metastases Local control of treated metastases at 6-, 12-, and 18-mo was 94\% (95\% CI: $0.56-0.80), 88 \%$ (95\% CI: $0.25-0.51$ ), and $84 \%$ (95\% CI: $0.13-0.38)$, respectively

TA B L E 3 Univariate and multivariate analysis for Local control

\begin{tabular}{|c|c|c|c|c|c|c|}
\hline & \multicolumn{3}{|c|}{ Univariate } & \multicolumn{3}{|c|}{ Multivariable } \\
\hline & HR & $95 \% \mathrm{CI}$ & $P$ value & HR & $95 \% \mathrm{CI}$ & $P$ value \\
\hline Age & 1.05 & $0.93-1.20$ & 0.373 & - & - & - \\
\hline PS & 2.26 & $0.91-5.58$ & 0.076 & - & - & - \\
\hline NCCN class risk & 0.62 & $00.18-2.09$ & 0.450 & - & - & - \\
\hline Time to metastases & 1.00 & 0.98-1.01 & 0.787 & - & - & - \\
\hline $\begin{array}{l}\text { Time to biochemical } \\
\text { relapse }\end{array}$ & 1.00 & $0.98-1.01$ & 0.656 & - & - & - \\
\hline Site of metastases & 2.13 & $0.70-6.47$ & 0.182 & - & - & - \\
\hline $\begin{array}{l}\text { Number of treated } \\
\text { metastases }\end{array}$ & 0.51 & $0.11-2.24$ & 0.374 & - & - & - \\
\hline $\begin{array}{l}\text { Oligorecurrence vs } \\
\text { oligoprogressive }\end{array}$ & 9.10 & $1.00-82.32$ & 0.049 & 8.71 & $0.88-85.8$ & 0.064 \\
\hline Time to SBRT & 1.03 & $1.00-1.07$ & 0.047 & 1.03 & $0.99-1.07$ & 0.055 \\
\hline PSA before SBRT & 1.04 & $0.95-1.12$ & 0.339 & - & - & - \\
\hline $\begin{array}{l}\text { Systemic treatment } \\
\text { during SBRT }\end{array}$ & 1.37 & $0.34-5.50$ & 0.654 & - & - & - \\
\hline $\begin{array}{l}\text { Lines of systemic } \\
\text { treatments }\end{array}$ & 0.98 & $0.52-1.86$ & 0.966 & - & - & - \\
\hline $\begin{array}{l}\text { Castration sensitive } \\
\text { vs resistant }\end{array}$ & 0.72 & $0.14-3.57$ & 0.688 & - & - & - \\
\hline ADT before SBRT & 1.48 & $0.35-6.21$ & 0.588 & - & - & - \\
\hline
\end{tabular}

F I G U RE 2 Kaplan-Meier of Progression Free Survival. Rates of Progression Free Survival at 6-, 12-, and 18-mo were 70\% (95\% CI: $56 \%-80 \%$ ), $38 \%$ (95\% CI: $25 \%-51 \%$ ), and $25 \%$ (95\% CI: $13 \%-38 \%$ ) experienced a worse PFS compared to castration sensitive group (HR 2.12, 95\% CI: 1.11-4.03; $P=0.021$ ). Rates of PFS at 6-, 12-, and 18- months were 76\% (95\% CI: 60\%$86 \%$ ), $46 \%$ (95\% CI: $29 \%-61 \%$ ), and $32 \%$ (95\% CI: $17 \%$ $48 \%)$, respectively for castration sensitive, and 56\% (95\% CI: $30 \%-75 \%), 16 \%$ (95\% CI: $2 \%-40 \%)$, and $8 \%$ (95\% CI: $0-30 \%$ ) for castration resistant subgroup (Figure 3). Median PFS for castration resistant patients was 6.3 months vs
9.8 months for castration sensitive group. All patients were alive at the moment of the analysis.

\section{DISCUSSION}

Here we assessed the impact of SBRT in oligometastatic PC patients. We evaluated 64 patients with 90 metastases 


\begin{tabular}{|c|c|c|c|c|c|c|}
\hline & \multicolumn{3}{|c|}{ Univariate } & \multicolumn{3}{|c|}{ Multivariable } \\
\hline & HR & 95\% CI & $P$ value & HR & $95 \% \mathrm{CI}$ & $P$ value \\
\hline Age & 0.97 & 0.93-1.02 & 0.354 & - & - & - \\
\hline PS & 0.82 & $0.51-1.33$ & 0.434 & - & - & - \\
\hline NCCN class risk & 0.70 & $0.40-1.21$ & 0.205 & - & - & - \\
\hline Time to metastases & 0.99 & $0.99-1.00$ & 0.402 & - & - & - \\
\hline $\begin{array}{l}\text { Time to biochemical } \\
\text { relapse }\end{array}$ & 0.99 & $0.98-1.00$ & 0.253 & - & - & - \\
\hline Site of metastases & 1.01 & $0.51-2.00$ & 0.955 & - & - & - \\
\hline $\begin{array}{l}\text { Number of treated } \\
\text { metastases }\end{array}$ & 1.59 & $0.94-2.70$ & 0.081 & - & - & - \\
\hline $\begin{array}{l}\text { Oligorecurrence vs } \\
\text { oligoprogressive }\end{array}$ & 3.03 & $0.39-23.05$ & 0.283 & - & - & - \\
\hline Time to SBRT & 1.00 & 0.98-1.02 & 0.526 & - & - & - \\
\hline PSA before SBRT & 1.02 & 0.98-1.06 & 0.297 & - & - & - \\
\hline $\begin{array}{l}\text { Systemic treatment } \\
\text { during SBRT }\end{array}$ & 1.79 & $0.97-3.29$ & 0.061 & - & - & - \\
\hline $\begin{array}{l}\text { Lines of systemic } \\
\text { treatments }\end{array}$ & 1.37 & $0.84-2.22$ & 0.199 & - & - & - \\
\hline $\begin{array}{l}\text { Castration sensitive } \\
\text { vs resistant }\end{array}$ & 2.12 & $1.11-4.03$ & 0.021 & 2.12 & $1.11-4.03$ & 0.021 \\
\hline ADT before SBRT & 1.38 & $0.75-2.55$ & 0.295 & - & - & - \\
\hline
\end{tabular}

T A B L E 4 Univariate and multivariate analysis for PFS

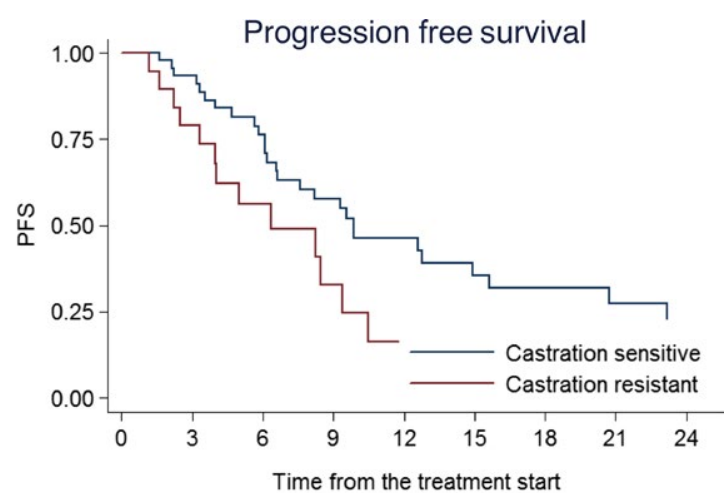

Number at risk Castration sensitive 45 Castration resistant 19

$\begin{array}{cccc}29 & 14 & 8 & 5 \\ 8 & 2 & 1 & 1\end{array}$

F I G U RE 3 Kaplan-Meier of Progression Free Survival according to sensitivity to hormonal therapy. Progression Free Survival at 6-, 12-, and 18 -mo were $76 \%$ (95\% CI: $60 \%-86 \%$ ), $46 \%$ (29\%-61\%), and 32\% (17\%-48\%), respectively, for castration sensitive, and 56\% (30\%-75\%), $16 \%(2 \%-40 \%)$, and $8 \%(0 \%-30 \%)$ for castration resistant subgroup

undergoing high dose ablative RT. The results showed a LC rate of $88 \%$ at 1 year. High local control rates are reported in literature in this setting. Ahmed et al ${ }^{16}$ and Habl et al, ${ }^{20}$ observed a similar $100 \%$ of local control when treating 17 and 15 patients respectively. Muacevic et al. ${ }^{14}$ treated 64 bone metastases with single fraction SBRT reaching a rate of local control of $95.5 \%$. Recently, Ost et al published a prospective randomized study comparing surveillance with metastasis-directed therapy for oligometastatic PC. The analysis showed that the median ADT-free survival was 13 months for the surveillance and 21 months for the treatment group $(P=0.11)$. $^{21}$

Control of limited burden of disease could be a relevant point in PC patients, in whom the number of metastases are considered an important prognostic factor. ${ }^{22,23}$ Globally we observed control of treated disease for a median time of 14.1 months; the time was prolonged to 15.9 months in patients who didn't experienced in-field progression. Oligoprogressive patients seem to be characterized by a worse LC, however this data could be affected by imbalance in the sample, being only two patients in oligoprogression. Time to SBRT correlated to the response to local treatment, indeed the effect is quite light with an increased risk of $3 \%$. Main question is the identification of patients actually oligometastatic who can benefit from SBRT as local approach. In our study, PFS value at 18 months was $25 \%$, with high percentiles reaching $38 \%$. Data are in line with the one reported for other solid tumor, about $35 \%$ of PFS at 2 years. ${ }^{24}$

The majority of our patients relapse out-field after 18 months (63\%) with about 50\% after the first year. The addition of systemic treatment to SBRT seems to not affect the out-field progression in our sample. These results confirm the need to better understand the selection of patients who can benefit from SBRT or the advantage to associate 
systemic treatments to radiotherapy. Our results are consistent with those published by other authors. For example Habl et $\mathrm{al}^{20}$ reported that ADT had no impact on PFS, time to initiation of ADT, or to intensification of systemic therapy. Also Jereczek-fossa et $\mathrm{al}^{25}$ demonstrated that time to progression after SBRT for nodal metastases was similar whether androgen deprivation was added or not (11 vs 10 months).

According to our analysis, PFS seems to be worse in castration resistant PC. One year PFS rates were $46 \%$ (29\%-61\%) for ADT sensitive patients vs $16 \%$ (2\%-40\%) for castration resistant patients. For several years the only available treatment for castration resistant PC was chemotherapy, in particular docetaxel. Only in the recent decade the introduction of new generation hormonal therapies improved outcome of this subset of patients. The efficacy of abiraterone and enzalutamide has been proved by several prospective randomized trials, both in pre and postchemotherapy setting. ${ }^{26-31}$ The AFFIRM trial ${ }^{30}$ that investigate the use of Enzalutamide postdocetaxel demonstrated a radiographic PFS (rPFS) of 8.3 months against 5.4 months of placebo. The COU-AA- $301^{31}$ explored the efficacy of abiraterone in the same setting and demonstrated a rPFS 5.6 (2.0 in placebo). Higher rates of PFS are reported by trials of prechemotherapy setting (rPFS of 16.5 months of COUAA-302 trial $^{27}$ and median not reached in PREVAIL triall ${ }^{28}$ ). The castration resistant patients treated in our study reached a median rPFS of 8.4 months. Patients diagnosed as castration resistant when treated with SBRT are more likely to have subclinical disease that becomes evident during posttreatment follow-up. However the role of local treatment in metastatic castration resistant prostate cancer patients has not been investigated, including the addition of new generation hormonal therapy to SBRT.

The present study is limited by several issues, including its retrospective nature and the short duration of follow-up, due to which we were not able to analyze the impact on overall survival.

\section{5 | CONCLUSIONS}

Our results confirm that SBRT in an effective treatment for oligorecurrent and oligoprogressive metastases from PC. Ablative RT could be beneficial in the oligometastatic setting where the treated metastases can sometimes be the only burden of disease. However studies of association of SBRT with systemic therapies, including new generation hormonal therapy, are necessary. The combination of new hormonal therapy and SBRT could potentially give the best results in selected patients.

\section{CONFLICT OF INTEREST}

There are no conflict of interest disclosures from any authors.
ORCID

Ciro Franzese (D) http://orcid.org/0000-0001-6893-6284

Paolo Andrea Zucali (D) http://orcid. org/0000-0002-2274-1702

Davide Franceschini (D) http://orcid. org/0000-0003-1142-2439

\section{REFERENCES}

1. Hellman S, Weichselbaum RR. Oligometastases. J Clin Oncol. 1995;13(1):8-10.

2. Hellman S, Weichselbaum RR. Oligometastases revisited page_5. Nat Rev Clin Oncol. 2011;8:378-382.

3. Harada M, Iida M, Yamaguchi M, Shida K. Analysis of bone metastasis of prostatic adenocarcinoma in 137 autopsy cases. Adv Exp Med Biol. 1992;324:173-182.

4. Tabata KI, Niibe Y, Satoh T, et al. Radiotherapy for oligometastases and oligo-recurrence of bone in prostate cancer. Pulm Med. 2012;2012:541656.

5. Berkovic P, De Meerleer G, Delrue L, et al. Salvage stereotactic body radiotherapy for patients with limited prostate cancer metastases: deferring androgen deprivation therapy. Eur Urol Suppl. 2012;11(5):189.

6. Ost P, Jereczek-Fossa BA, Van As N, et al. Progression-free survival following stereotactic body radiotherapy for oligometastatic prostate cancer treatment-naive recurrence: a multi-institutional analysis. Eur Urol. 2016;69(1):9-12.

7. Singh D, Yi WSW, Brasacchio RA, et al. Is there a favourable subset of patients with prostate cancer who develop oligometastases? Int J Radiat Oncol Biol Phys. 2004;58(1):3-10.

8. Khoo V. Is there another bite of the cherry? The case for radical local therapy for oligometastatic disease in prostate cancer. Eur Urol. 2016;69(1):13-14.

9. Evangelista L, Briganti A, Fanti S, et al. New clinical indications for $18 \mathrm{~F} / 11 \mathrm{C}$-choline, new tracers for positron emission tomography and a promising hybrid device for prostate cancer staging: a systematic review of the literature. Eur Urol. 2016;70(1):161-175.

10. Graziani T, Ceci F, Castellucci P, et al. 11C-Choline PET/ CT for restaging prostate cancer. Results from 4,426 scans in a single-centre patient series. Eur J Nucl Med Mol Imaging. 2016;43(11):1971-1979.

11. Sobol I, Zaid HB, Haloi R, et al. Contemporary mapping of postprostatectomy prostate cancer relapse with ${ }^{11} \mathrm{c}$-choline positron emission tomography and multiparametric magnetic resonance imaging. J Urol. 2017;197(1):129-134.

12. De Bruycker A, Lambert B, Claeys T, et al. Prevalence and prognosis of low-volume, oligorecurrent, hormone-sensitive prostate cancer amenable to lesion ablative therapy. BJU Int. 2017;120(6):815-821.

13. Duchesne G, Bassett J, D'Este C, et al. TROG 03.06 and VCOG PR 01-03: the "Timing of Androgen Deprivation Therapy in Prostate Cancer Patients with a Rising PSA (TOAD)" collaborative randomised phase III trial. J Med Imaging Radiat Oncol. 2015;59:17-18.

14. Muacevic A, Kufeld M, Rist C, Wowra B, Stief C, Staehler M. Safety and feasibility of image-guided robotic radiosurgery for 
patients with limited bone metastases of prostate cancer. Urol Oncol Semin Orig Investig. 2013;31(4):455-460.

15. Schick U, Jorcano $S$, Nouet $P$, et al. Androgen deprivation and high-dose radiotherapy for oligometastatic prostate cancer patients with less than five regional and/or distant metastases Androgen deprivation and high-dose radiotherapy for regional and/or distant metastases. Acta Oncol. 2013;52(8):1622-1628.

16. Ahmed KA, Barney BM, Davis BJ, Park SS, Kwon ED, Olivier KR. Stereotactic body radiation therapy in the treatment of oligometastatic prostate cancer. Front Oncol. 2013;2:215.

17. Decaestecker K, De Meerleer G, Lambert B, et al. Repeated stereotactic body radiotherapy for oligometastatic prostate cancer recurrence. Radiat Oncol. 2014;9:135.

18. Wahl RL, Jacene H, Kasamon Y, Lodge MA. From RECIST to PERCIST: evolving considerations for PET response criteria in solid tumors. J Nucl Med. 2009;50(Suppl 1):122S-150S.

19. Scher HI, Morris MJ, Stadler WM, et al. Trial Design and objectives for castration-resistant prostate cancer: updated recommendations from the prostate cancer clinical trials working group 3. $J$ Clin Oncol. 2016;34(12):1402-1418.

20. Habl G, Straube C, Duma MN, et al. Oligometastases from Prostate Cancer: local treatment with stereotactic body radiotherapy (SBRT). Strahlentherapie und Onkol. 2017;193(1):S69-S70.

21. Ost P, Reynders D, Decaestecker K, et al. Surveillance or metastasis-directed therapy for oligometastatic prostate cancer recurrence: a prospective, randomized, multicenter phase II trial. J Clin Oncol. 2017;36(5):446-453.

22. Schweizer MT, Zhou XC, Wang $\mathrm{H}$, et al. Association of metastasis-free survival (MFS) with overall survival (OS) in men with PSA-recurrent prostate cancer treated with deferred androgen-deprivation therapy. J Clin Oncol. 2013;31(6):109.

23. Ost P, Decaestecker K, Lambert B, et al. Prognostic factors influencing prostate cancer-specific survival in non-castrate patients with metastatic prostate cancer. Prostate. 2014;74(3):297-305.

24. Tree AC, Khoo VS, Eeles RA, et al. Stereotactic body radiotherapy for oligometastases. Lancet Oncol. 2013;14:e28-e37.
25. Jereczek-Fossa BA, Beltramo G, Fariselli L, et al. Robotic imageguided stereotactic radiotherapy, for isolated recurrent primary, lymph node or metastatic prostate cancer. Int J Radiat Oncol Biol Phys. 2012;82(2):889-897.

26. Ryan CJ, Smith MR, de Bono JS, et al. Abiraterone in Metastatic Prostate Cancer without Previous Chemotherapy. N Engl J Med. 2013;368(2):138-148.

27. Rathkopf DE, Smith MR, De Bono JS, et al. Updated interim efficacy analysis and long-term safety of abiraterone acetate in metastatic castration-resistant prostate cancer patients without prior chemotherapy (COU-AA-302). Eur Urol. 2014;66(5): 815-825.

28. Beer TM, Armstrong AJ, Rathkopf DE, et al. Enzalutamide in metastatic prostate cancer before chemotherapy. $N$ Engl J Med. 2014;371(5):424-433.

29. de Bono JS, Logothetis CJ, Molina A, et al. Abiraterone and increased survival in metastatic prostate cancer. $N$ Engl J Med. 2011;364(21):1995-2005.

30. Scher HI, Fizazi K, Saad F, et al. Increased survival with enzalutamide in prostate cancer after chemotherapy. $N$ Engl J Med. 2012;367(13):1187-1197.

31. Fizazi K, Scher HI, Molina A, et al. Abiraterone acetate for treatment of metastatic castration-resistant prostate cancer: final overall survival analysis of the COU-AA-301 randomised, double-blind, placebo-controlled phase 3 study. Lancet Oncol. 2012;13(10):983-992.

How to cite this article: Franzese C, Zucali PA, Di

Brina L, et al. The efficacy of Stereotactic body radiation therapy and the impact of systemic treatments in oligometastatic patients from prostate cancer. Cancer Med. 2018;7:4379-4386. https://doi.org/10.1002/ cam4.1707 